Article

\title{
Thermal Properties of Methyl Ester-Containing Poly(2-oxazoline)s
}

\author{
Petra J. M. Bouten ${ }^{1,2}$, Kathleen Lava ${ }^{1}$, Jan C. M. van Hest ${ }^{2, *}$ and Richard Hoogenboom ${ }^{1, *}$ \\ Received: 13 August 2015 ; Accepted: 30 September 2015 ; Published: 13 October 2015 \\ Academic Editor: Graeme Moad \\ 1 Supramolecular Chemistry Group, Department of Organic and Macromolecular Chemistry, \\ Ghent University, Krijgslaan 281 S4, 9000 Ghent, Belgium; petra.bouten@ugent.be (P.J.M.B.); \\ kathleen.lava@ugent.be (K.L.) \\ 2 Radboud University Nijmegen, Institute for Molecules and Materials (IMM), Heyendaalseweg 135, \\ 6525 AJ Nijmegen, The Netherlands \\ * Correspondence: j.vanhest@science.ru.nl (J.C.M.H.); richard.hoogenboom@ugent.be (R.H.)
}

\begin{abstract}
This paper describes the synthesis and thermal properties in solution and bulk of poly(2-alkyl-oxazoline)s (PAOx) containing a methyl ester side chain. Homopolymers of 2-methoxycarbonylethyl-2-oxazoline (MestOx) and 2-methoxycarbonylpropyl-2-oxazoline (C3MestOx), as well as copolymers with 2-ethyl-2-oxazoline (EtOx) and 2-n-propyl-2-oxazoline (nPropOx), with systematic variations in composition were prepared. The investigation of the solution properties of these polymers revealed that the cloud point temperatures $\left(T_{C P} \mathrm{~s}\right)$ could be tuned in between $24{ }^{\circ} \mathrm{C}$ and $108{ }^{\circ} \mathrm{C}$ by variation of the PAOx composition. To the best of our knowledge, the $T_{C P S}$ of PMestOx and PC3MestOx are reported for the first time and they closely resemble the $T_{C P}$ S of PEtOx and PnPropOx, respectively, indicating similar hydrophilicity of the methyl ester and alkyl side chains. Furthermore, the thermal transitions and thermal stability of these polymers were investigated by DSC and TGA measurements, respectively, revealing amorphous polymers with glass transition temperatures between $-1{ }^{\circ} \mathrm{C}$ and $54{ }^{\circ} \mathrm{C}$ that are thermally stable up to $>300^{\circ} \mathrm{C}$.
\end{abstract}

Keywords: poly(2-oxazoline)s; copolymers; LCST; cloud point temperature; thermal properties; glass transition temperature

\section{Introduction}

Smart polymeric materials can change their physical properties in response to external stimuli, such as temperature, ionic strength, $\mathrm{pH}$, chemical and biological stimuli, light or electromagnetic radiation [1-3]. Thermoresponsive polymeric behavior has most extensively been studied and, in particular, polymers that undergo a temperature induced phase transition. One of the best-characterized thermoresponsive polymers is poly( $\mathrm{N}$-isopropyl acrylamide) (PNIPAAm), which displays a lower critical solution temperature (LCST) of $32{ }^{\circ} \mathrm{C}$, just below body temperature [2-5]. Other classes of thermoresponsive polymers that have emerged in recent years are for example poly(oligo ethylene glycol acrylate)s [2,6], polyisocyanopeptides grafted with oligo(ethylene glycol) side chains [7-9], poly(2-oxazine)s [10] and poly(2-oxazoline)s [3,5,11-17]. These types of polymers can be applied in temperature sensors, [18] protein chromatography [19] and various biomedical applications such as drug delivery and tissue engineering $[1,20]$. For these latter applications thermoresponsive polymers are needed that are biocompatible and that can be conveniently functionalized.

A polymer class that fulfills these requirements is the class of poly(2-alkyl/aryl-2-oxazoline)s (PAOx) as they are biocompatible, thermoresponsive, and have tunable properties $[15,21,22]$. 
Poly(2-methyl-2-oxazoline) (PMeOx) and poly(2-ethyl-2-oxazoline) (PEtOx) are interesting for biomedical applications because they show stealth behaviour similar to poly(ethylene glycol) (PEG) [15,21-25]. Furthermore, PEtOx and poly(2-propyl-2-oxazoline)s (PPropOx) show thermoresponsive properties. PEtOx has an LCST of $\sim 60{ }^{\circ} \mathrm{C}$, poly(2-n-propyl-2-oxazoline) (PnPropOx) of $\sim 25^{\circ} \mathrm{C}$, poly(2-cyclopropyl-2-oxazoline) (PcPropOx) of $\sim 30^{\circ} \mathrm{C}$ and poly(2-isopropyl2-oxazoline) (PiPropOx) of $\sim 38^{\circ} \mathrm{C}[3,5,15,26]$. Cloud point temperatures $\left(T_{C P} s\right)$ can be tuned from $9{ }^{\circ} \mathrm{C}$ to $100^{\circ} \mathrm{C}$ by varying the molecular weight and composition of the polymer by incorporation of more hydrophobic or hydrophilic monomeric units, either by copolymerization or post-polymerization modification $[5,11-13,27,28]$.

Functional groups, often protected, can be introduced into PAOx by making use of a functional monomer or initiator during the living cationic ring opening polymerisation (CROP, Scheme 1) of 2-oxazoline monomers or by using a functional terminating agent, yielding well-defined PAOx with control over number and type of functionalities [15,29-38]. Methyl esters are especially interesting, because they can undergo a direct amidation with a variety of amines to easily introduce other functional groups such as alcohols, hydrazide and amines [39-42]. Moreover, the ester can be hydrolyzed to the corresponding carboxylic acid providing a versatile handle for conjugation as well as a means to introduce $\mathrm{pH}$ responsiveness. Although the potential of side-chain methyl ester-containing PAOx copolymers is well established, there is remarkably little known about their thermal features and thermoresponsive behavior [33,43-47].

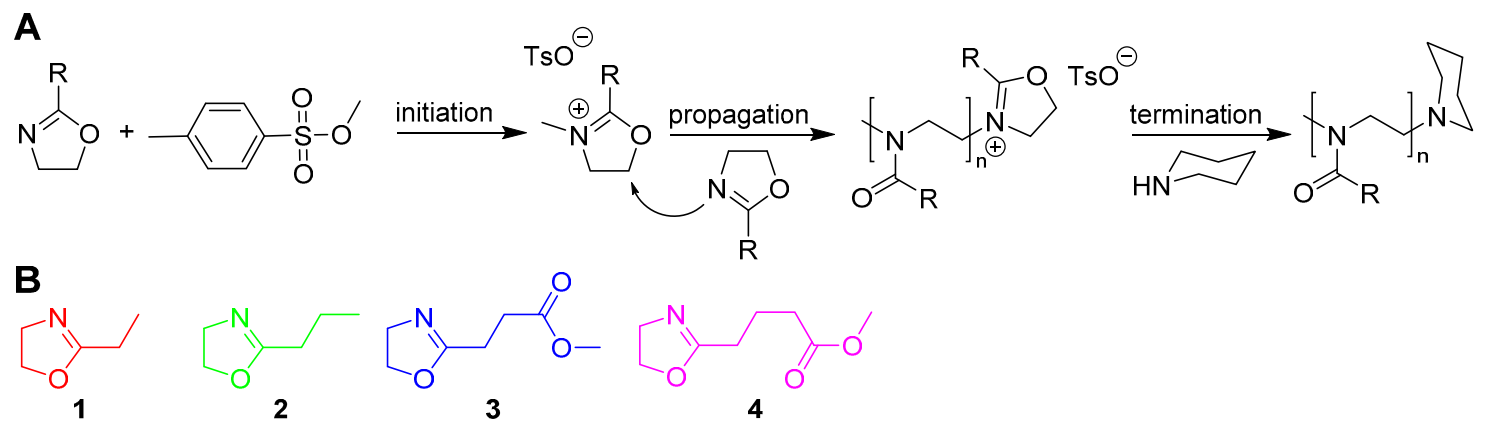

Scheme 1. (A) Cationic ring-opening polymerisation of 2-oxazolines with methyl p-toluenesulfonate as initiator and piperidine as terminating agent and (B) Monomer structures of EtOx (1), $n \operatorname{PropOx}(\mathbf{2})$, MestOx (3) and C3MestOx (4).

In this paper we describe the synthesis and thermal properties of methyl ester-containing PAOx. Homopolymers and statistical copolymers, with near ideal random monomer distributions [38], of 2-ethyl-2-oxazoline (EtOx, 1) and 2-n-propyl-2-oxazoline (nPropOx, 2) with 2-methoxycarbonylethyl-2-oxazoline (MestOx, 3) and 2-methoxycarbonylpropyl-2-oxazoline (C3MestOx, 4) were prepared with 10, 20, 30, 50, and 70 mol \% methyl ester content. The thermal solution and bulk properties of these polymers were determined by turbidimetry, differential scanning calorimetry (DSC), and thermal gravimetric analysis (TGA), respectively.

\section{Experimental Section}

\subsection{Materials}

2-Chloroethylamine hydrochloride, methyl p-toluenesulfonate (MeOTs), and sodium carbonate were purchased from Acros Organics. EtOx was kindly donated by Polymer Chemistry Innovations. All other reagents were purchased from Sigma Aldrich and used as received. EtOx and methyl $p$-toluenesulfonate (MeOTs) were purified by distillation over barium oxide and stored under argon. Dry solvents were obtained from a solvent purification system from J.C. Meyer, with aluminum oxide 
drying system and a nitrogen flow. MestOx [37], C3MestOx [38], and $n$ PropOx [48] were prepared according to literature procedures.

\subsection{Instrumentation}

Nuclear magnetic resonance (NMR) spectra were recorded on a Bruker DMC300 (300 MHz for ${ }^{1} \mathrm{H}, 75 \mathrm{MHz}$ for ${ }^{13} \mathrm{C}$ ) (Bruker: Billerica, MA, USA).

Polymerization reaction mixtures were prepared in a VIGOR Sci-Lab SG 1200/750 Glovebox system (Vigor: Houston, TX, USA), with purity levels of less than $1 \mathrm{ppm}$ for $\mathrm{O}_{2}$ and $\mathrm{H}_{2} \mathrm{O}$.

Polymerizations were carried out in a Biotage Initiator Microwave System with Robot Sixty utilizing capped reaction vials. These vials were heated to $120^{\circ} \mathrm{C}$ overnight, allowed to cool to room temperature and filled with nitrogen prior to use. All microwave polymerizations were performed with temperature control (IR sensor).

Size exclusion chromatography (SEC) was performed on an Agilent 1260 (Agilent Technologies: Santa Clara, CA, USA): series HPLC system equipped with a 1260 online degasser, a 1260 ISO-pump, a 1260 automatic liquid sampler, a temperature controlled column compartment, a 1260 diode array detector (DAD) and a 1260 refractive index detector (RID). Analyses were performed on a PSS Gram30 column (PSS Polymer Standards Service GmbH: Mainz, Germany) in series with a PSS Gram1000 column at $50{ }^{\circ} \mathrm{C}$. $\mathrm{N}, \mathrm{N}$-dimethylacetamide (DMA, Sigma-Aldrich: Zwijndrecht, The Netherlands), containing $50 \mathrm{mM}$ of $\mathrm{LiCl}$, was used as an eluent, at a flow rate of $0.593 \mathrm{~mL} \cdot \mathrm{min}^{-1}$. The SEC traces were analyzed using the Agilent Chemstation software with the GPC add on. Number average molecular weights $\left(M_{n}\right)$ and dispersity $(\boxplus)$ values were calculated against poly(methyl methacrylate) PMMA standards.

Turbidity measurements were performed on an Avantium Crystal 16 platform (Avantium: Geleen, The Netherlands). Solutions of the polymers were prepared in milliQ (WaterPro PS polisher from Labconco: Kansas City, MO, USA) water with a conductivity of $18.2 \mathrm{M} \Omega / \mathrm{cm}^{\prime}$ at $5 \mathrm{mg} \cdot \mathrm{mL}^{-1}$ and were stirred at room temperature until all polymer was dissolved. Three heating cycles were applied with a heating/cooling rate of $1^{\circ} \mathrm{C} \cdot \mathrm{min}^{-1}$, temperature ranges of 5-45, 20-60, 20-75, 60-105 or $70-110{ }^{\circ} \mathrm{C}$ were used depending on the polymer, and withhold steps of $5 \mathrm{~min}$ at the extreme low temperatures, no hold time was applied when the samples were heated above $100{ }^{\circ} \mathrm{C}$; all measurements were performed with a stirring rate of $700 \mathrm{rpm}$. The cloud point temperatures are given as the $50 \%$ transmittance point during heating. GC vials with open caps and septa were used for these measurements allowing heating until $110{ }^{\circ} \mathrm{C}$ with minor pressure build up as noticed by slight expansion of the septum.

Differential scanning calorimetry (DSC) traces were recorded under nitrogen with a Mettler-Toledo DSC1 module. Glass transition temperatures were obtained from the second heating run with heating/cooling rates of $10^{\circ} \mathrm{C} \cdot \mathrm{min}^{-1}$. Indium was used as a standard for temperature and enthalpy calibrations.

Thermogravimetric analysis (TGA) was performed with a Mettler Toledo TGA/SDTA851e instrument (Mettler Toledo: Columbus, $\mathrm{OH}, \mathrm{USA}$ ) under nitrogen atmosphere at a heating rate of $10^{\circ} \mathrm{C} \cdot \mathrm{min}^{-1}$ between $25^{\circ} \mathrm{C}$ and $800^{\circ} \mathrm{C}$.

\subsection{Polymer Synthesis}

Polymerization mixtures with a total monomer concentration of $4 \mathrm{M}$ in acetonitrile, an overall $[\mathrm{M}] /[\mathrm{I}]$ ratio of 100 and MeOTs as initiator, were prepared in the glovebox under argon and the reactor vials were crimped air-tight inside the glovebox. Polymerizations were carried out under microwave irradiation at $140^{\circ} \mathrm{C}$ for $20 \mathrm{~min}$ aiming for full conversion [37,38]. After cooling to room temperature, the polymerizations were quenched by the addition of piperidine. After removal of the solvents under reduced pressure, the polymers were re-dissolved in dichloromethane and precipitated in cold diethyl ether twice. The polymers were dried in the vacuum oven at $50{ }^{\circ} \mathrm{C}$ before further analysis. 


\section{Results and Discussion}

Series of homopolymers and copolymers of EtOx and nPropOx with MestOx and C3MestOx were prepared $[37,38]$ with varying feed ratios of 10, 20, 30, 50, and $70 \mathrm{~mol} \%$ MestOx or C3MestOx and a constant monomer to initiator ratio of $[\mathrm{M}] /[\mathrm{I}]=100$, yielding four sets of copolymers. All polymers were terminated with piperidine instead of the widely used methanolic sodium hydroxide to avoid saponification of the methyl ester. All polymers were characterized by ${ }^{1} \mathrm{H}$ NMR spectroscopy and SEC and were obtained with the desired composition and a narrow dispersity $(\nexists<1.21$, Table 1$)$.

Cloud point temperatures $\left(T_{C P} s\right)$ of the homo- and copolymers were determined by turbidimetry of $5 \mathrm{mg} \cdot \mathrm{mL}^{-1}$ aqueous solutions, under stirring as this gives more reliable dissolution data when cooling down the samples. All polymers, expect $\mathrm{EtOx}_{49}-\mathrm{MestOx}_{51}$, showed reversible LCST behavior covering a broad temperature range $\left(24-108^{\circ} \mathrm{C}\right.$, Table 1$)$ depending on the polymer composition with nearly no hysteresis between heating and cooling cycles (See Supplementary Information Figures S1-S21). In some cases the $T_{C P}$ in the cooling cycles was slightly higher than in the heating cycles; this can be possibly explained by the fact that re-dissolution of these polymers was a rather slow process, leading to temporary lower concentrations in solution during cooling and thus an increase of $T_{\mathrm{CP}}$. However, the precipitates were fully dissolved when the solution cooled down completely.

Interestingly, the homopolymers of MestOx (PMestOx) and C3MestOx (PC3MestOx) also showed thermo-responsive properties. PMestOx displayed a shallow transition with a $T_{C P}$ of $102{ }^{\circ} \mathrm{C}$ and $80 \%$ transmission at $92{ }^{\circ} \mathrm{C}$ similar to PEtOx with a degree of polymerization of 100 (Figure $1 \mathrm{~A}$ ), whereas PC3MestOx exhibits a sharp transition at $26^{\circ} \mathrm{C}$ (Figure 1B) comparable to PnPropOx. When the polymers were heated above $100{ }^{\circ} \mathrm{C}$ during the turbidimetry measurements, the $T_{\mathrm{CP}}$ slightly increased during every run (Figure 1 and Figures S2-S11 in Supplementary Information), which is ascribed to partial hydrolysis of the methyl ester groups resulting in the corresponding carboxylic acid, as was confirmed by ${ }^{1} \mathrm{H}$ NMR spectroscopy (Supplementary Information Figures S22, S23). Partial precipitation or crystallization of the sample could be excluded after visual inspection of the samples. The determined average $T_{C P}$ of all heating and cooling cycles are reported in Table 1, except for the polymers that were heated above $100{ }^{\circ} \mathrm{C}$ for which the $T_{C P}$ in the first heating and cooling runs are listed.

A

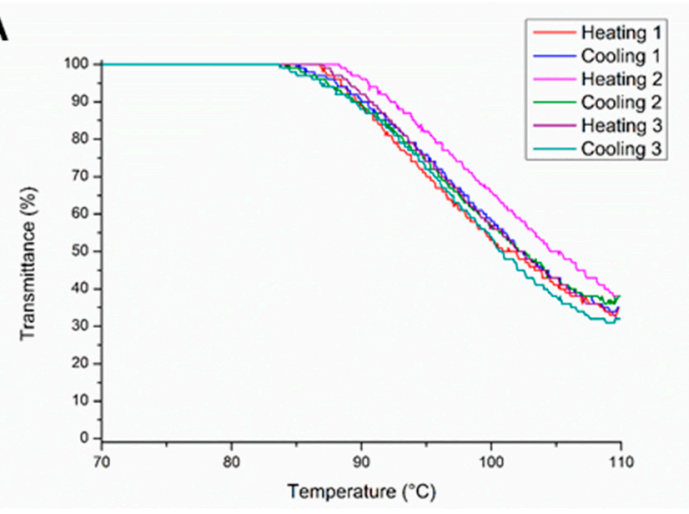

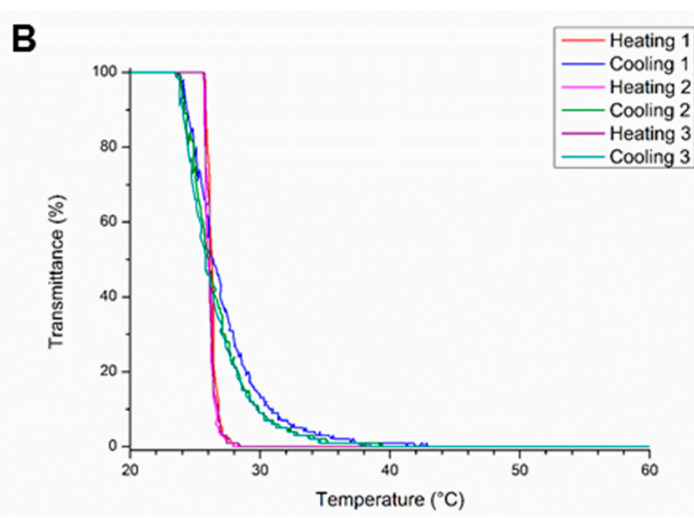

Figure 1. Turbidity measurements for (A) PMestOx and (B) PC3MestOx.

The $T_{C P}$ s of the different copolymers (Table 1) are plotted as a function of the copolymer composition in Figure 2. The relationship between the $T_{C P S}$ and EtOx content of the EtOx-C3MestOx copolymers is linear (Figure $2 \mathrm{~A}$ ), and, thus with this monomer combination the $\mathrm{T}_{\mathrm{CP}}$ can straightforwardly be tuned between the $T_{C P S}$ of the corresponding homopolymers by varying the polymer composition. A linear relationship between copolymer composition and $T_{C P}$ was previously also described for $\mathrm{P}(\mathrm{iPropOx}-n$ PropOx), $\mathrm{P}(\mathrm{iPropOx}-\mathrm{E} \mathrm{O} O \mathrm{x})$ and $\mathrm{P}(\mathrm{cPropOx}-\mathrm{EtOx})$ copolymers $[13,14,27]$. 
Table 1. Overview of synthesis and characterisation data of studied (co)polymers.

\begin{tabular}{|c|c|c|c|c|c|c|c|c|c|c|}
\hline \multirow{2}{*}{ Monomer 1} & \multirow{2}{*}{ Monomer 2} & \multirow{2}{*}{$\begin{array}{c}\text { Feed ratio } \\
\text { (M1:M2) }\end{array}$} & \multirow{2}{*}{$\begin{array}{l}\text { Composition }{ }^{a} \\
\text { (M1:M2) }\end{array}$} & \multicolumn{2}{|l|}{ SEC $^{b}$} & \multicolumn{2}{|c|}{$T_{C P}\left({ }^{\circ} \mathrm{C}\right)^{\mathrm{c}}$} & \multirow{2}{*}{$T_{g}{ }^{\mathrm{d}}\left({ }^{\circ} \mathrm{C}\right)$} & \multicolumn{2}{|c|}{ TGA $\left({ }^{\circ} \mathrm{C}\right)^{\mathrm{e}}$} \\
\hline & & & & $M_{n}\left(10^{3} \mathrm{~g} / \mathrm{mol}\right)$ & $\boxplus$ & Heating & Cooling & & $5 \%$ & $50 \%$ \\
\hline MestOx & - & $100: 0$ & 100:0 & 19.4 & 1.10 & 101 & 102 & 39 & 258 & 353 \\
\hline C3MestOx & - & $100: 0$ & $100: 0$ & 24.1 & 1.12 & 26 & 26 & -1 & 325 & 360 \\
\hline $\mathrm{EtOx} *$ & - & 100:0 & 100:0 & $14.0^{*}$ & $1.19 *$ & 91 * & $91 *$ & $54 *$ & - & - \\
\hline$n$ PropOx & - & 100:0 & 100:0 & 16.6 & 1.10 & 27 & 23 & 35 & 312 & 406 \\
\hline EtOx & MestOx & $90: 10$ & $91: 9$ & 18.9 & 1.14 & 93 & 96 & 53 & 322 & 403 \\
\hline $\mathrm{EtOx}$ & MestOx & $80: 20$ & $82: 18$ & 16.9 & 1.14 & 99 & 102 & 45 & 293 & 389 \\
\hline EtOx & MestOx & $70: 30$ & $70: 30$ & 17.4 & 1.13 & 103 & 106 & 44 & 310 & 376 \\
\hline $\mathrm{EtOx}$ & MestOx & $50: 50$ & $49: 51$ & 19.3 & 1.14 & \# & $\#$ & 39 & 306 & 365 \\
\hline $\mathrm{EtOx}$ & MestOx & $30: 70$ & $29: 71$ & 22.8 & 1.16 & 102 & 104 & 38 & 296 & 359 \\
\hline$n$ PropOx & MestOx & $90: 10$ & $90: 10$ & 21.0 & 1.12 & 25 & 24 & 30 & 327 & 393 \\
\hline$n$ PropOx & MestOx & $80: 20$ & $79: 21$ & 15.5 & 1.12 & 27 & 30 & 30 & 306 & 385 \\
\hline$n$ PropOx & MestOx & $70: 30$ & $68: 32$ & 16.3 & 1.13 & 32 & 36 & 30 & 303 & 377 \\
\hline$n$ PropOx & MestOx & $50: 50$ & $48: 52$ & 20.6 & 1.15 & 40 & 40 & 32 & 310 & 367 \\
\hline$n$ PropOx & MestOx & $30: 70$ & $27: 73$ & 29.3 & 1.19 & 55 & 54 & 35.0 & 309 & 367 \\
\hline EtOx & C3MestOx & $90: 10$ & $90: 10$ & 21.1 & 1.13 & 89 & 89 & 43 & 334 & 399 \\
\hline EtOx & C3MestOx & $80: 20$ & $82: 18$ & 21.8 & 1.14 & 78 & 79 & 39 & 313 & 382 \\
\hline EtOx & C3MestOx & $70: 30$ & $70: 30$ & 21.6 & 1.14 & 71 & 78 & 27 & 316 & 377 \\
\hline EtOx & C3MestOx & $50: 50$ & $50: 50$ & 22.7 & 1.14 & 56 & 56 & 17 & 322 & 369 \\
\hline EtOx & C3MestOx & $30: 70$ & $30: 70$ & 24.1 & 1.14 & 42 & 43 & -2 & 320 & 363 \\
\hline$n$ PropOx & C3MestOx & $90: 10$ & $90: 10$ & 19.2 & 1.21 & 24 & 25 & 28 & 321 & 399 \\
\hline$n$ PropOx & C3MestOx & $80: 20$ & $79: 21$ & 20.7 & 1.15 & 25 & 32 & 18 & 328 & 385 \\
\hline$n$ PropOx & C3MestOx & $70: 30$ & $68: 32$ & 21.0 & 1.15 & 25 & 31 & 15 & 332 & 379 \\
\hline$n$ PropOx & C3MestOx & $50: 50$ & $48: 52$ & 16.7 & 1.21 & 26 & 27 & 12 & 311 & 368 \\
\hline$n$ PropOx & C3MestOx & $30: 70$ & $28: 72$ & 18.8 & 1.16 & 25 & 30 & 5 & 304 & 361 \\
\hline
\end{tabular}

${ }^{*}$ Literature values [27]; \# no cloud point temperature observed up to $110^{\circ} \mathrm{C} ;{ }^{\text {a }}$ determined by ${ }^{1} \mathrm{H}$ NMR spectroscopy; ${ }^{\mathrm{b}}$ determined by SEC against PMMA standards; ${ }^{\mathrm{c}}$ determined by turbidimetry measurements; ${ }^{\mathrm{d}}$ determined by DSC measurements; $5 \%$ : loss of $5 \mathrm{wt} \%$ after loss of solvents; for some polymers it was difficult to determine the point where all solvents were removed and for these the start of the flatter area was used for calculation of the $5 \%$ weight loss temperature. $50 \%$ : loss of $50 \mathrm{wt} \%$ from the total mass. 
All $T_{C P} \mathrm{~S}$ of the $n$ PropOx-C3MestOx copolymers were in between 24 and $26.5{ }^{\circ} \mathrm{C}$ (Figure 2B), revealing that varying the polymer composition hardly changed the thermo-responsive behavior. This behavior was expected as the hydrophobicity of both monomers and the $T_{C P} s$ of the homopolymers are comparable.

In the $n$ PropOx-MestOx copolymer series, the $T_{C P} S$ exponentially increased with increasing MestOx content (Figure 2C), also the $80 \%$ transmission values are plotted in this graph, showing comparable $T_{C P}$ values for the copolymers and a clear difference for PMestOx. A similar trend was also reported for EtOx- $n$ PropOx copolymers $[14,28]$. The hydrophobic $n$ PropOx monomer seems to be more dominant in determining the overall polymer hydrophilicity and $T_{C P}$ than the hydrophilic MestOx monomer.

A

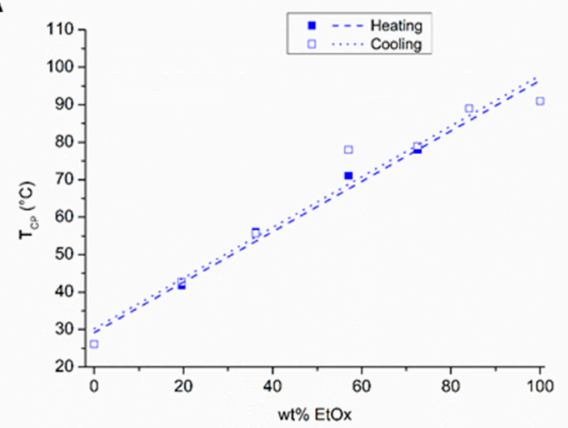

C

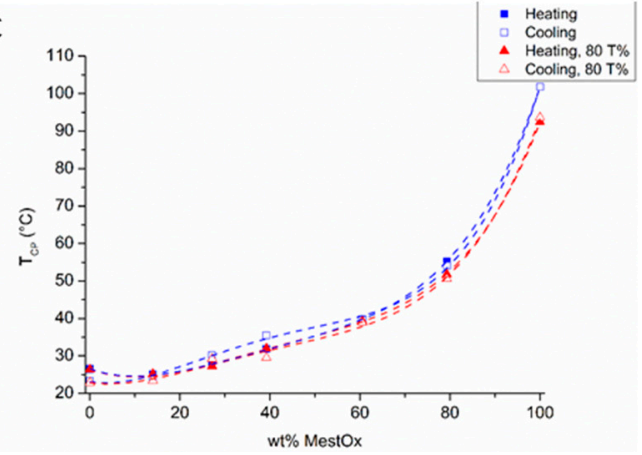

B

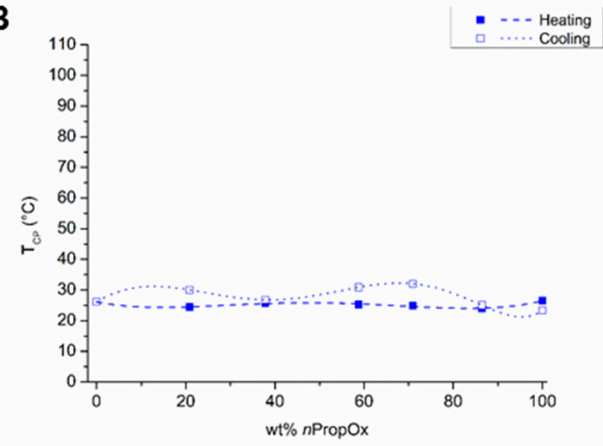

D

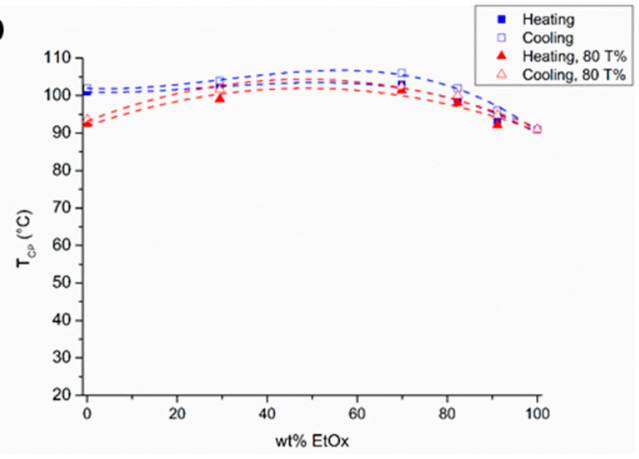

Figure 2. Cloud point temperatures $\left(\mathrm{T}_{\mathrm{CP}}\right.$; determined at $50 \%$ transmittance unless otherwise stated) as a function of polymer composition of (A) P(EtOx-C3MestOx), (B) P(nPropOx-C3MestOx), (C) $\mathrm{P}(n$ PropOx-MestOx, and (D) $\mathrm{P}($ EtOx-MestOx $)$; lines are added to guide the eye.

Copolymers of EtOx and MestOx displayed $T_{C P}$ s in between $93{ }^{\circ} \mathrm{C}$ and $103{ }^{\circ} \mathrm{C}$ at EtOx-MestOx comonomer ratios of 90:10, 80:20, 70:30, and 30:70 (Figure 2D, Table 1), whereas surprisingly the copolymer with a 50:50 comonomer ratio did not show a transition up to $110{ }^{\circ} \mathrm{C}$. Additionally, here the $80 \%$ transmission values are plotted in this graph, showing comparable $T_{C P}$ values for the copolymers and a clear difference for PMestOx. This observation indicates more efficient polymer hydration and/or decreased polymer-polymer interactions, which both may be related to near random placement of the smaller ethyl and larger methoxycarbonylethyl side chains.

The thermal bulk properties of the homo- and copolymers were further investigated by differential scanning calorimetry (DSC) and thermogravimetric analysis (TGA). All polymers showed a clear glass transition (Figure 3, ESI Figure S24-S27, Table 1), indicating that they are amorphous. The $T_{g} \mathrm{~S}$ of the homopolymers PMestOx $\left(T_{g}=39^{\circ} \mathrm{C}\right)$ and PnPropOx $\left(T_{g}=35^{\circ} \mathrm{C}\right)$ are comparable, while PC3MestOx has a $T_{g}$ of $-1{ }^{\circ} \mathrm{C}$ and PEtOx has a $T_{g}$ of $54^{\circ} \mathrm{C}$. The rather low $T_{g}$ of PC3MestOx indicates high chain mobility induced by the side chain. 


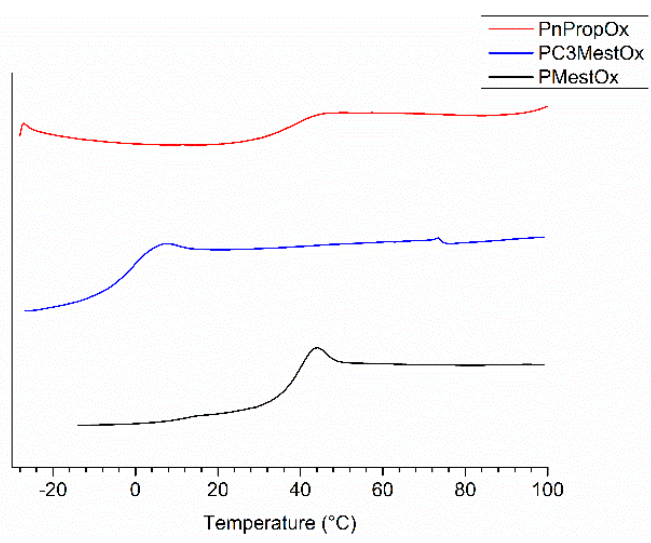

Figure 3. DSC traces of second heating run $\left(10 \mathrm{~K} \cdot \mathrm{min}^{-1}\right)$ of PMestOx, PC3MestOx, and PnPropOx homopolymers.

The $T_{g} \mathrm{~s}$ of the copolymers are plotted in Figure 4. In the P(EtOx-MestOx) copolymer series, the $T_{g} \mathrm{~s}$ did not change much up to $40 \mathrm{wt} \%$ EtOx (Figure $4 \mathrm{~A}$ ) and from this point on it increased linearly towards the $T_{g}$ of PEtOx. The $T_{g}$ of the MestOx homopolymer is slightly higher than the $T_{g}$ of $\mathrm{P}(\mathrm{EtOx}-\mathrm{MestOx}, 30: 70)$, indicating that the polymer chain mobility is lower, which may be ascribed to more efficient (dipole-dipole) interactions between the polyamide backbones in the homopolymers. A very similar trend in $T_{g}$ was observed for $\mathrm{P}(\mathrm{EtOx}-\mathrm{C} 3 \mathrm{MestOx})$ copolymers (Figure 4B), with the exception that after already $20 \mathrm{wt} \%$ incorporation of EtOx the glass transition temperature started to increase linearly with increasing amount of EtOx, possibly due to the larger difference in $T_{g}$ of the homopolymers.

A

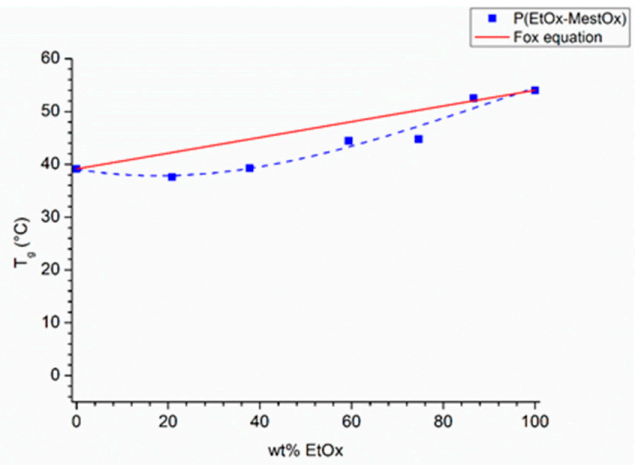

C

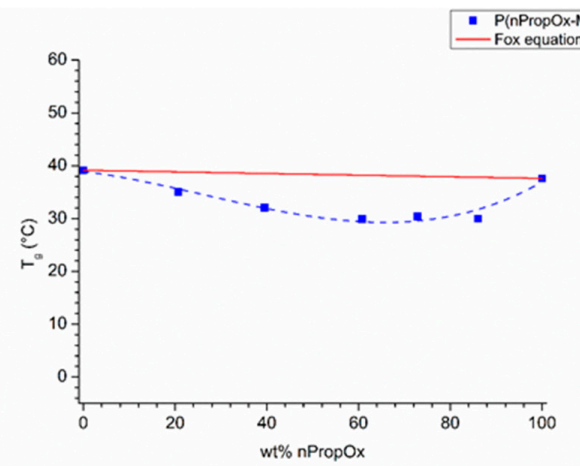

B

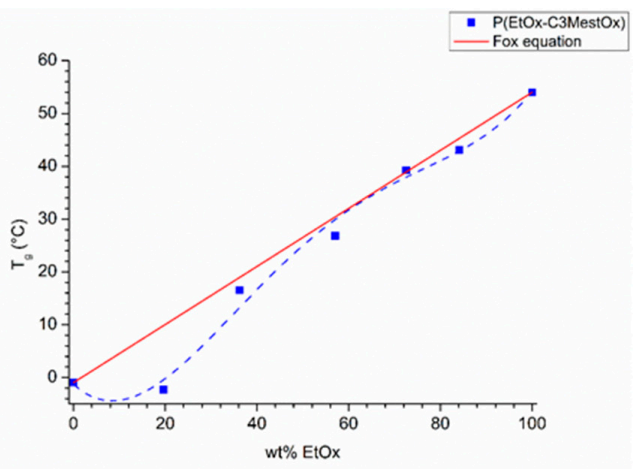

D

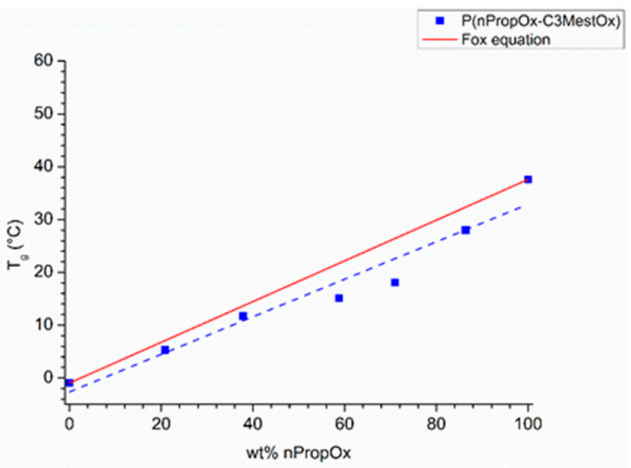

Figure 4. Glass transition temperatures as function of polymer composition of (A) $\mathrm{P}(\mathrm{EtOx}-\mathrm{MestOx})$, (B) P(EtOx-C3MestOx), (C) P(nPropOx-MestOx), and (D) P(nPropOx-C3MestOx). Lines are added to guide the eye; the red line indicates the Fox equation. 
For the $\mathrm{P}(n$ PropOx-MestOx $)$ copolymers all measured $T_{g} \mathrm{~s}$ were lower than those of the homopolymers (Figure $4 \mathrm{C}$ ) and the $T_{g} s$ only vary $5{ }^{\circ} \mathrm{C}$ within the composition range. A similar trend was recently reported for copolymers of 2-cyclopropyl-2-oxazoline (cPropOx) and EtOx [27], and this can be ascribed to suppression of interchain interactions in the copolymers. The $T_{g}$ of nPropOx-C3MestOx copolymers increased linearly with increasing $n$ PropOx content (Figure 4D), so with this combination of monomers the glass transition can be accurately tuned between the $T_{g} \mathrm{~s}$ of the corresponding homopolymers by varying the monomer ratios.

TGA analysis revealed that the PMestOx homopolymer was thermally stable up to $250{ }^{\circ} \mathrm{C}$ (Figure 5A), while all other homo- and copolymers were stable at least up to $300{ }^{\circ} \mathrm{C}$ (Figure 5, Table 1, and Figures S28-S30 in Supplementary Information). The lower stability of PMestOx is rather surprising, especially compared to $\mathrm{PC} 3 \mathrm{MestOx}$ and may indicate that the close proximity of the secondary amide to the ester group decreases the stability of the latter. In Table 1 the temperature for $5 \%$ and $50 \%$ weight loss are listed, whereby the $5 \mathrm{wt} \%$ loss was determined after the loss of solvents. However, not all polymers show a plateau after loss of solvent and for these the start of the flatter area was used for calculation of the 5\% weight loss temperature. The $50 \%$ loss is reported as the $50 \%$ loss of the total weight. In general, when more (C3)MestOx was incorporated into the copolymers, the thermal stability slightly decreased, because the $\mathrm{P}(\mathrm{C} 3) \mathrm{MestOx}$ homopolymers are less stable than PEtOx or PnPropOx homopolymers, most likely due to decomposition of the methyl ester units.

A

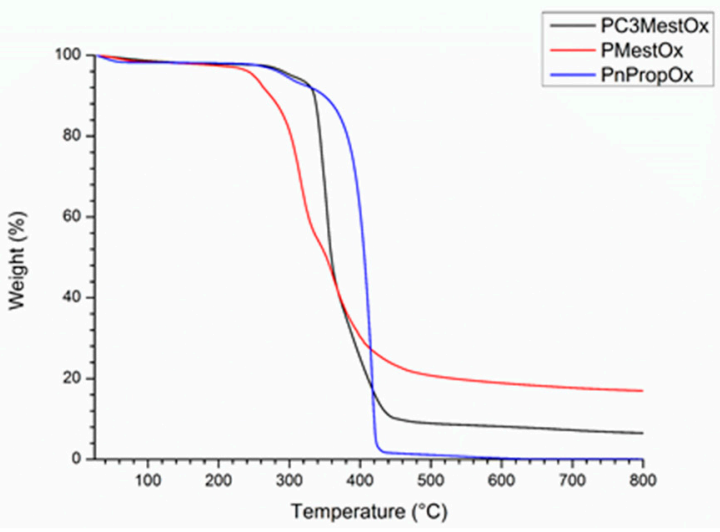

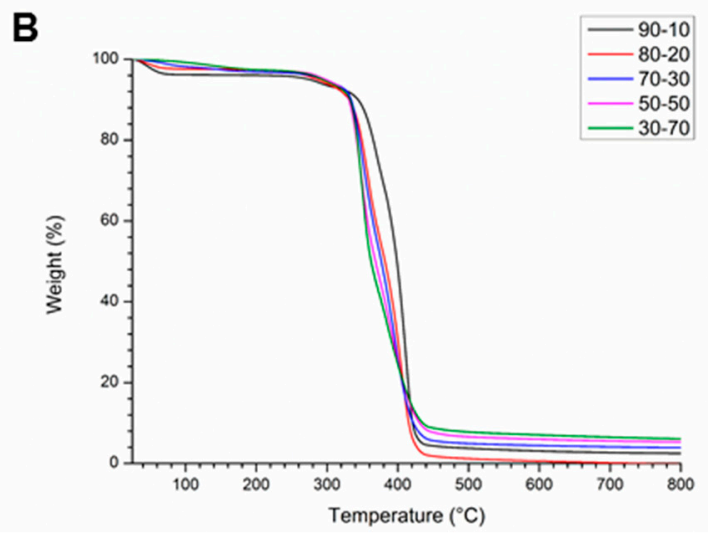

Figure 5. Thermogravimetric analysis of (A) PMestOx, PC3MestOx, and PnPropOx homopolymers and (B) $\mathrm{P}($ EtOx-C3MestOx) copolymers.

\section{Conclusions}

Homo- and copolymers of MestOx and C3MestOx with EtOx and nPropOx were successfully synthesized. All polymers, except $\mathrm{P}\left(\mathrm{EtOx}_{49}-\mathrm{MestOx}_{51}\right)$, showed $T_{C P} \mathrm{~S}$ that varied in between $24{ }^{\circ} \mathrm{C}$ and $108{ }^{\circ} \mathrm{C}$ depending on the composition, at a concentration of $5 \mathrm{mg} / \mathrm{mL}$ in water. Interestingly, PC3MestOx has a low $T_{C P}$ of $26^{\circ} \mathrm{C}$ making it interesting for biomedical applications. DSC measurements revealed that all polymers are amorphous with $T_{g} s$ between $-1{ }^{\circ} \mathrm{C}$ and $54{ }^{\circ} \mathrm{C}$. For $\mathrm{P}(\mathrm{EtOx}-\mathrm{MestOx}), \mathrm{P}(\mathrm{EtOx}-\mathrm{C} 3 \mathrm{MestOx})$, and $\mathrm{P}(n \mathrm{PropOx}-\mathrm{C} 3 \mathrm{MestOx})$ copolymers the glass transition temperature can be tuned in between the $T_{g} s$ of the homopolymers. However, for $\mathrm{P}\left(n\right.$ PropOx-MestOx) copolymers, the $T_{g} \mathrm{~s}$ of all copolymers are lower than the ones of both homopolymers, indicating suppression of interchain interactions. All homo- and copolymers are thermally stable up to at least $250{ }^{\circ} \mathrm{C}$, whereby copolymers with more (C3)MestOx were found to be less stable. Nonetheless, the stabilities will allow thermal processing, e.g. hot-melt extrusion, at temperatures well above room temperature.

Supplementary Information: The supplementary information is available online at: www.mdpi.com/2073-4360/7/10/1494/s1. 
Acknowledgments: The authors acknowledge the Polymer Innovation Program (PIPM10006, General adhesive Tissue Tape) and the Special Research Fund of Ghent University; in particular PB for a joint PhD fellowship.

Author Contributions: The work was designed by Petra J. M. Bouten, Jan C. M. van Hest and Richard Hoogenboom. Petra J. M. Bouten performed the kinetic experiments and turbidimetry studies. Kathleen Lava performed the thermal analysis. The article was written by Petra J. M. Bouten; Kathleen Lava, Jan C. M. van Hest and Richard Hoogenboom corrected this paper.

Conflicts of Interest: The authors declare no conflict of interest.

\section{References}

1. Ward, M.A.; Georgiou, T.K. Thermoresponsive polymers for biomedical applications. Polymers 2011, 3, 1215-1242. [CrossRef]

2. Vancoillie, G.; Frank, D.; Hoogenboom, R. Thermoresponsive poly(oligo ethylene glycol acrylates). Prog. Polym. Sci. 2014, 39, 1074-1095. [CrossRef]

3. Roy, D.; Brooks, W.L.A.; Sumerlin, B.S. New directions in thermoresponsive polymers. Chem. Soc. Rev. 2013, 42, 7214-7243. [CrossRef] [PubMed]

4. Schild, H.G. Poly(n-isopropylacrylamide): Experiment, theory and application. Prog. Polym. Sci. 1992, 17, 163-249. [CrossRef]

5. Weber, C.; Hoogenboom, R.; Schubert, U.S. Temperature responsive bio-compatible polymers based on poly(ethylene oxide) and poly(2-oxazoline)s. Prog. Polym. Sci. 2012, 37, 686-714. [CrossRef]

6. Lutz, J.-F. Thermo-switchable materials prepared using the oegma-platform. Adv. Mater. 2011, 23, 2237-2243. [CrossRef]

7. Kouwer, P.H.J.; Koepf, M.; Le Sage, V.A.A.; Jaspers, M.; van Buul, A.M.; Eksteen-Akeroyd, Z.H.; Woltinge, T.; Schwartz, E.; Kitto, H.J.; Hoogenboom, R.; et al. Responsive biomimetic networks from polyisocyanopeptide hydrogels. Nature 2013, 493, 651-655. [CrossRef] [PubMed]

8. Koepf, M.; Kitto, H.J.; Schwartz, E.; Kouwer, P.H.J.; Nolte, R.J.M.; Rowan, A.E. Preparation and characterization of non-linear poly(ethylene glycol) analogs from oligo(ethylene glycol) functionalized polyisocyanopeptides. Eur. Polym. J. 2013, 49, 1510-1522. [CrossRef]

9. Hu, G.; Li, W.; Hu, Y.; Xu, A.; Yan, J.; Liu, L.; Zhang, X.; Liu, K.; Zhang, A. Water-soluble chiral polyisocyanides showing thermoresponsive behavior. Macromolecules 2013, 46, 1124-1132. [CrossRef]

10. Bloksma, M.M.; Paulus, R.M.; van Kuringen, H.P.C.; van der Woerdt, F.; Lambermont-Thijs, H.M.L.; Schubert, U.S.; Hoogenboom, R. Thermoresponsive poly(2-oxazine)s. Macromol. Rapid Commun. 2012, 33, 92-96. [CrossRef] [PubMed]

11. Huber, S.; Jordan, R. Modulation of the lower critical solution temperature of 2-alkyl-2-oxazoline copolymers. Colloid. Polym. Sci. 2008, 286, 395-402. [CrossRef]

12. Diehl, C.; Schlaad, H. Thermo-responsive polyoxazolines with widely tuneable lcst. Macromol. Biosci. 2009, 9, 157-161. [CrossRef] [PubMed]

13. Park, J.-S.; Kataoka, K. Precise control of lower critical solution temperature of thermosensitive poly(2-isopropyl-2-oxazoline) via gradient copolymerization with 2-ethyl-2-oxazoline as a hydrophilic comonomer. Macromolecules 2006, 39, 6622-6630. [CrossRef]

14. Park, J.-S.; Kataoka, K. Comprehensive and accurate control of thermosensitivity of poly(2-alkyl-2-oxazoline)s via well-defined gradient or random copolymerization. Macromolecules 2007, 40, 3599-3609. [CrossRef]

15. Hoogenboom, R. Poly(2-oxazoline)s: A polymer class with numerous potential applications. Angew. Chem. Int. Ed. 2009, 48, 7978-7994. [CrossRef] [PubMed]

16. Zhang, N.; Luxenhofer, R.; Jordan, R. Thermoresponsive poly(2-oxazoline) molecular brushes by living ionic polymerization: Modulation of the cloud point by random and block copolymer pendant chains. Macromol. Chem. Phys. 2012, 213, 1963-1969. [CrossRef]

17. Luxenhofer, R.; Huber, S.; Hytry, J.; Tong, J.; Kabanov, A.V.; Jordan, R. Chiral and water-soluble poly(2-oxazoline)s. J. Polym. Sci. Polym. Chem. 2013, 51, 732-738. [CrossRef]

18. Sambe, L.; de La Rosa, V.R.; Belal, K.; Stoffelbach, F.; Lyskawa, J.; Delattre, F.; Bria, M.; Cooke, G.; Hoogenboom, R.; Woisel, P. Programmable polymer-based supramolecular temperature sensor with a memory function. Angew. Chem. Int. Ed. 2014, 53, 5044-5048. 
19. Kanazawa, H. Temperature-responsive polymers for liquid-phase separations. Anal. Bioanal. Chem. 2004, 378, 46-48. [CrossRef] [PubMed]

20. Gaertner, F.C.; Luxenhofer, R.; Blechert, B.; Jordan, R.; Essler, M. Synthesis, biodistribution and excretion of radiolabeled poly(2-alkyl-2-oxazoline)s. J. Control. Release 2007, 119, 291-300. [CrossRef] [PubMed]

21. Luxenhofer, R.; Han, Y.; Schulz, A.; Tong, J.; He, Z.; Kabanov, A.V.; Jordan, R. Poly(2-oxazoline)s as polymer therapeutics. Macromol. Rapid Commun. 2012, 33, 1613-1631. [CrossRef] [PubMed]

22. Sedlacek, O.; Monnery, B.D.; Filippov, S.K.; Hoogenboom, R.; Hruby, M. Poly(2-oxazoline)s-Are they more advantageous for biomedical applications than other polymers? Macromol. Rapid Commun. 2012, 33, 1648-1662. [CrossRef] [PubMed]

23. Zalipsky, S.; Hansen, C.B.; Oaks, J.M.; Allen, T.M. Evaluation of blood clearance rates and biodistribution of poly(2-oxazoline)-grafted liposomes. J. Pharm. Sci. 1996, 85, 133-137. [CrossRef] [PubMed]

24. Mero, A.; Pasut, G.; Via, L.D.; Fijten, M.W.M.; Schubert, U.S.; Hoogenboom, R.; Veronese, F.M. Synthesis and characterization of poly(2-ethyl 2-oxazoline)-conjugates with proteins and drugs: Suitable alternatives to peg-conjugates? J. Control. Release 2008, 125, 87-95. [CrossRef] [PubMed]

25. Luxenhofer, R.; Sahay, G.; Schulz, A.; Alakhova, D.; Bronich, T.K.; Jordan, R.; Kabanov, A.V. Structure-property relationship in cytotoxicity and cell uptake of poly(2-oxazoline) amphiphiles. J. Control. Release 2011, 153, 73-82. [CrossRef] [PubMed]

26. Bloksma, M.M.; Weber, C.; Perevyazko, I.Y.; Kuse, A.; Baumgärtel, A.; Vollrath, A.; Hoogenboom, R.; Schubert, U.S. Poly(2-cyclopropyl-2-oxazoline): From rate acceleration by cyclopropyl to thermoresponsive properties. Macromolecules 2011, 44, 4057-4064. [CrossRef]

27. Glassner, M.; Lava, K.; de la Rosa, V.R.; Hoogenboom, R. Tuning the lcst of poly(2-cyclopropyl-2-oxazoline) via gradient copolymerization with 2-ethyl-2-oxazoline. J. Polym. Sci. Polym. Chem. 2014, 52, 3118-3122. [CrossRef]

28. Hoogenboom, R.; Thijs, H.M.L.; Jochems, M.J.H.C.; van Lankvelt, B.M.; Fijten, M.W.M.; Schubert, U.S. Tuning the lcst of poly(2-oxazoline)s by varying composition and molecular weight: Alternatives to poly(n-isopropylacrylamide)? Chem. Commun. 2008, 44, 5758-5760. [CrossRef] [PubMed]

29. Guillerm, B.; Monge, S.; Lapinte, V.; Robin, J.J. How to modulate the chemical structure of polyoxazolines by appropriate functionalization. Macromol. Rapid Commun. 2012, 33, 1600-1612. [CrossRef] [PubMed]

30. Volet, G.; Lav, T.X.; Babinot, J.; Amiel, C. Click-chemistry: An alternative way to functionalize poly(2-methyl-2-oxazoline). Macromol. Chem. Phys. 2011, 212, 118-124. [CrossRef]

31. Rossegger, E.; Schenk, V.; Wiesbrock, F. Design strategies for functionalized poly(2-oxazoline)s and derived materials. Polymers 2013, 5, 956-1011.

32. Fijten, M.W.M.; Haensch, C.; van Lankvelt, B.M.; Hoogenboom, R.; Schubert, U.S. Clickable poly(2-oxazoline)s as versatile building blocks. Macromol. Chem. Phys. 2008, 209, 1887-1895. [CrossRef]

33. Levy, A.; Litt, M. Polymerization of cyclic iminoethers. V. 1,3-oxazolines with hydroxy- acetoxy- and carboxymethyl-alkyl groups in 2 position and their polymers. J. Polym. Sci. Polym. Chem. 1968, 6, 1883-1894. [CrossRef]

34. Taubmann, C.; Luxenhofer, R.; Cesana, S.; Jordan, R. First aldehyde-functionalized poly(2-oxazoline)s for chemoselective ligation. Macromol. Biosci. 2005, 5, 603-612. [CrossRef] [PubMed]

35. Gress, A.; Volkel, A.; Schlaad, H. Thio-click modification of poly [2-(3-butenyl)-2-oxazoline]. Macromolecules 2007, 40, 7928-7933. [CrossRef]

36. Kelly, A.M.; Hecke, A.; Wirnsberger, B.; Wiesbrock, F. Synthesis of poly(2-oxazoline)-based hydrogels with tailor-made swelling degrees capable of stimuli-triggered compound release. Macromol. Rapid Commun. 2011, 32, 1815-1819. [CrossRef] [PubMed]

37. Bouten, P.J.M.; Hertsen, D.; Vergaelen, M.; Monnery, B.D.; Boerman, M.A.; Goossens, H.; Catak, S.; van Hest, J.C.M.; van Speybroeck, V.; Hoogenboom, R. Accelerated living cationic ring-opening polymerization of a methyl ester functionalized 2-oxazoline monomer. Polym. Chem. 2015, 6, 514-518. [CrossRef]

38. Bouten, P.J.M.; Hertsen, D.; Vergaelen, M.; Monnery, B.M.; Catak, S.; van Hest, J.C.M.; van Speybroeck, V.; Hoogenboom, R. Synthesis of poly(2-oxazoline)s with side chain methyl ester functionalities: Detailed understanding of copolymerization behavior of methyl ester containing monomers with 2-alkyl-2-oxazolines. J. Polym. Sci. Polym. Chem. 2015. accepted. [CrossRef]

39. Hoogenboom, R. Polyoxazoline polymers and methods for their preparation conjugates of these polymers and medical uses thereof. WO 2013/103297 A1, 11 July 2013. 
40. Mees, M.; Hoogenboom, R. Functional poly(2-oxazoline)s by direct amidation of methyl ester side chains. Macromolecules 2015, 48, 3531-3538. [CrossRef]

41. Grogna, M.; Cloots, R.; Luxen, A.; Jerome, C.; Desreux, J.F.; Detrembleur, C. Design and synthesis of novel DOTA $\left(\mathrm{Gd}^{3}+\right)$-polymer conjugates as potential mri contrast agents. J. Mater. Chem. 2011, 21, 12917-12926. [CrossRef]

42. Steunenberg, P.; Könst, P.M.; Scott, E.L.; Franssen, M.C.R.; Zuilhof, H.; Sanders, J.P.M. Polymerisation of $\beta$-alanine through catalytic ester-amide exchange. Eur. Polym. J. 2013, 49, 1773-1781. [CrossRef]

43. Zarka, M.T.; Nuyken, O.; Weberskirch, R. Amphiphilic polymer supports for the asymmetric hydrogenation of amino acid precursors in water. Chem. Eur. J. 2003, 9, 3228-3234. [CrossRef] [PubMed]

44. Kotre, T.; Zarka, M.T.; Krause, J.O.; Buchmeiser, M.R.; Weberskirch, R.; Nuyken, O. Design and application of amphiphilic polymeric supports for micellar catalysis. Macromol. Symp. 2004, 217, 203-214. [CrossRef]

45. Rueda, J.C.; Zschoche, S.; Komber, H.; Krahl, F.; Arndt, K.F.; Voit, B. New thermo-sensitive graft copolymers based on a poly ( $n$-isopropylacrylamide) backbone and functional polyoxazoline grafts with random and diblock structure. Macromol. Chem. Phys. 2010, 211, 706-716. [CrossRef]

46. Zschoche, S.; Rueda, J.C.; Binner, M.; Komber, H.; Janke, A.; Arndt, K.F.; Lehmann, S.; Voit, B. Reversibly switchable $\mathrm{pH}$ - and thermoresponsive core-shell nanogels based on poly(NiPAAm)-graft-poly(2-carboxyethyl-2-oxazoline)s. Macromol. Chem. Phys. 2012, 213, 215-226. [CrossRef]

47. Rueda, J.C.; Campos, E.; Komber, H.; Zschoche, S.; Haussler, L.; Voit, B. Synthesis and characterization of new $\mathrm{pH}$ - and thermo-responsive hydrogels based on $n$-isopropylacrylamide and 2-oxazolines. Des. Monomers Polym. 2014, 17, 208-216. [CrossRef]

48. Hoogenboom, R.; Fijten, M.W.M.; Thijs, H.M.L.; van Lankvelt, B.M.; Schubert, U.S. Microwave-assisted synthesis and properties of a series of poly(2-alkyl-2-oxazoline)s. Des. Monomers Polym. 2005, 8, 659-671. [CrossRef]

(C) 2015 by the authors; licensee MDPI, Basel, Switzerland. This article is an open access article distributed under the terms and conditions of the Creative Commons by Attribution (CC-BY) license (http:/ / creativecommons.org/licenses/by/4.0/). 